\title{
CARTA A PAULO FREIRE: COMO SUPERAR O ASSISTENCIALISMO POR MEIO DE UMA PRÁTICA EDUCATIVA COMO CARÁTER CRÍTICO-LIBERTADOR?
}

\author{
CARTA A PAULO FREIRE: ¿CÓMO SUPERAR EL ASISTENCIALISMO A TRAVÉS \\ DE LA PRÁCTICA EDUCATIVA COMO UN CARÁCTER CRÍTICO Y LIBERADOR?
}

\section{LETTER TO PAULO FREIRE: HOW TO OVERCOME ASSISTENTIALISM THROUGH EDUCATIONAL PRACTICE AS A CRITICAL AND LIBERATOR FEATURE?}

\author{
Sinval Martins FARINA ${ }^{1}$ \\ André Luis Castro de FREITAS ${ }^{2}$ \\ Luciane Albernaz de Araujo FREITAS ${ }^{3}$
}

RESUMO: O texto, em formato de carta, possui como intenção tecer aproximações ao pensamento de Paulo Freire de tal maneira que seja capaz de contribuir no processo de questionamentos e respostas acerca de um trabalho social vinculado a comunidades eclesiais de base. O referido trabalho social está relacionado a práticas que buscam superar o assistencialismo da doação de cestas básicas a famílias em situação de vulnerabilidade social e, também, é tema de pesquisa de doutorado. A partir de um estudo descritivo crítico, fundamentado em uma pesquisa qualitativa, bibliográfica, tem-se como objetivo refletir a partir do pensamento e testemunho de vida de Freire e, ainda, de autores que estudaram sua obra, sobre a formulação de encaminhamentos qualificados sobre a pesquisa de doutorado em Educação Ambiental.

PALAVRAS-CHAVE: Transformação social. Comunidade eclesial de base. Humanização.

RESUMEN: El texto, en formato de carta, tiene la intención de hacer aproximaciones al pensamiento de Paulo Freire de tal manera que pueda contribuir al proceso de preguntas y respuestas sobre el trabajo social vinculado a las comunidades eclesiales de base. El trabajo social está relacionado con prácticas que buscan superar la asistencia de donar alimentos a familias en situaciones de vulnerabilidad social y también es objeto de un proyecto de doctorado. Basado en un estudio descriptivo crítico, basado en una investigación bibliográfica cualitativa, el objetivo es reflexionar desde el pensamiento y el testimonio de la vida de Freire y los autores que estudiaron su trabajo, en la formulación de referencias calificadas sobre la investigación de Doctorado en Educación Ambiental.

PALAVRAS-CLAVE: Transformación social. Comunidad eclesial básica. Humanización.

${ }^{1}$ Universidade Federal do Rio Grande (FURG), Rio Grande - RS - Brasil. Doutorando no Programa de PósGraduação em Educação Ambiental. ORCID: https://orcid.org/0000-0002-7214-069X. E-mail: sinvalmfarina@gmail.com

${ }^{2}$ Universidade Federal do Rio Grande (FURG), Rio Grande - RS - Brasil. Professor Permanente do Programa de Pós-Graduação em Educação Ambiental. Doutor em Ciência da Computação (UFRGS) e em Educação (UFPEL). ORCID: https://orcid.org/0000-0002-4566-3655. E-mail: dmtalcf@ furg.br

${ }^{3}$ Instituto Federal Sul-Rio-Grandense (IFSUL), Pelotas - RS - Brasil. Docente. Doutora em Educação Ambiental. ORCID: https://orcid.org/0000-0001-9014-0071. E-mail: lucianel1968@gmail.com 
ABSTRACT: The text, in letter format, intends to build approximations to Paulo Freire's thinking in such a way that it is able to contribute to the process of questioning and answering about social work linked to base ecclesial communities. Social work is related to practices that seek to overcome the assistance of donating food to families in situations of social vulnerability and is also the subject of a doctoral project. Starting from a critical descriptive study, based on a qualitative, bibliographic research, the objective is to reflect from the thought and testimony of Freire's life and the authors who studied his work, on the formulation of qualified referrals related to doctoral research in Environmental Education.

KEYWORDS: Social transformation. Base ecclesial community. Humanization.

\section{Considerações iniciais}

Caro educador Paulo Freire é com muita alegria que faço esta comunicação com o senhor. Ainda que não diretamente, sei que meus colegas, assim como as leituras de suas obras e de obras sobre sua vida e escritos, ajudarão a responder aquilo que desejo saber. Sou um ser humano e educador que admira sua trajetória, história de vida, respostas às situações da vida e da educação, da profissão, da família, da cosmovisão, da política, da sensibilidade com os desprovidos de subsistência e de tantos outros direitos imprescindíveis à dignidade humana.

Vou rascunhar essa carta de forma direta, concedendo liberdade à razão e a emoção, para que também o senhor, por meio das formas anteriormente apontadas, possa expressar seu entendimento e opinião sobre os meus questionamentos.

Assisti a sua última entrevista, de 16 de abril, na qual foi lhe dirigida à questão de como o senhor gostaria de ser lembrado. Ao responder o senhor diz que quer ser lembrado como alguém que amou o mundo, as pessoas, a terra, a água e os animais.

Já em sua obra À sombra desta mangueira é possível ter presente sua profunda relação com a natureza, quando remete ao quintal de sua casa, como ser no e com o mundo e seus desdobramentos pelos tantos outros espaços em que pode estar presente. "O quintal de minha infância vem como que se desdobrando em tantos outros espaços, não necessariamente outros quintais. Sítios em que este homem de hoje, vendo em si aquele menino de ontem, aprende por ver melhor o antes visto" (FREIRE, 1995, p. 27).

Ao mesmo tempo, o senhor sempre deixou claro, a partir de seu sonho de liberdade, a necessidade de transformação em sua terra natal, o Brasil, em toda a sua concretude, considerando que a terra da gente é aquela que envolve, justamente, lutas por sonhos diferentes, na maioria das vezes antagônicos às relações profundamente desiguais entre as classes sociais.

Posso inferir que esse seu amor pelo mundo, pela natureza e pela gente, aproxima a terra, sua geografia, sua ecologia e sua biologia e, acima de tudo, cria a responsabilidade nos 
seres humanos para que façam uma história justa a partir das condições vividas e das possíveis transformações sociais.

Acredito oportuno relacionar nesse momento sua inserção no e com o mundo às discussões e práticas em educação ambiental pelo Brasil e pelo planeta, de tantas pessoas que, sabendo dos limites desse, tem lutado a favor da vida, individual e coletivamente.

A educação ambiental, por ter um eixo fundamental na relação sociedade-natureza, encara de forma utópica, isto é, vislumbra outra realidade, a construção da justiça social, pelo menos em sua tendência crítica e transformadora o sonho de uma nova sociedade está posto. Por isso, temas como pobreza, capitalismo, desemprego, fome, exclusão, racismo, entre tantos outros, assim como práticas e teorias transformadoras são objetos da práxis da educação ambiental transformadora.

A partir destas colocações tenho a ousadia de perguntar-lhe: como conhecedor dos pobres, das periferias e zonas rurais, e como alguém que se propôs a pensar e reinventar a educação nestes meios, que pistas o senhor indicaria para um trabalho de pesquisa num contexto desses? Considerando a periferia urbana na terceira década do século 21 com população desempregada e com fome.

O objetivo desta carta é pedir-lhe ajuda para construir o embasamento teórico e prático para um trabalho de pesquisa no contexto do desemprego e da fome na periferia urbana de uma cidade no sul do Rio Grande do Sul. Ano passado foi organizada uma formação com cerca de 60 participantes que são os agentes de cadastramento, acolhida e entrega de uma cesta mensal de alimentos não perecíveis para 130 famílias da comunidade citada. Os temas debatidos nas formações foram a educação popular, as relações interétnicas, a economia solidária e a diversidade religiosa.

A partir da leitura da obra Paulo Freire: uma biobibliografia destaco algumas ideias que poderão contribuir no sentido de responder à pergunta lançada ao senhor no contexto de uma pesquisa em construção. O seu pensamento, que traz a experiência, os afetos, o jeito de ser do nordeste brasileiro, em particular no início da década de 60, quando metade dos seus 30 milhões de habitantes vivia na "cultura do silêncio", isto é, eram analfabetos, teve por objetivo "dar-lhes a palavra", por meio da associação entre estudo, experiência de vida, trabalho, pedagogia e política.

Peço a sua licença, humildemente, para elencar aspectos da pequena parte de sua obra que até hoje pude conhecer, para que possamos dialogar tendo como horizonte os objetivos anteriormente apontados. Gostaria que o senhor fizesse correções, destaques ou comentários sobre aquilo que segue. 
A partir dessas considerações, compreendo que a carta está descrita da seguinte forma: A construção do conhecimento em Freire - faço uma discussão sobre a questão dos temas geradores e "situações-limites" a partir das relações dialógicas com vistas à compreensão e reflexão sobre o saber popular; Educação e política - realizo uma reflexão sobre a necessidade de que essas duas categorias da vida humana e social estejam em correlação e que a partir delas os seres humanos possam ter clareza de a favor de quem e de que se movimentam; Otimismo, fé e esperança - compreendo a importância de debater a questão da espiritualidade, da teologia da libertação e da sexualidade; Aprimorando a reflexão - correlaciono temas como ser mais, cultura do silêncio, o papel da teoria com o trabalho prático na comunidade eclesial de base e o paradigma ecológico. Após seguem as considerações finais e referências.

\section{A construção do conhecimento em Freire}

Depois da experiência da alfabetização ocorrida em Angicos, o senhor foi convidado pelo ministro da educação, Paulo de Tarso Santos, no governo João Goulart, para repensar a alfabetização de adultos no país. "Em 1964 estava prevista a instalação de 20 mil círculos de cultura para dois milhões de analfabetos. O golpe militar, no entanto, interrompeu os trabalhos bem no início e reprimiu toda a mobilização conquistada" (GADOTTI, 1996, p. 62).

O seu método de alfabetização pelo que pude entender até agora nasceu no interior do Movimento de Cultura Popular do Recife que, no final da década de 50, criara os chamados círculos de cultura. Estes não tinham uma programação feita a priori. A programação vinha de uma consulta aos grupos que estabeleciam os temas a serem debatidos. Cabia aos educadores tratar a temática que o grupo propunha.

Essa consulta nascia a partir do diálogo com esses sujeitos. Retomo Ghiggi (2010), o qual afirma que dentre as categorias centrais de sua obra está o diálogo. "Diálogo, que se realiza na dimensão política da educação, ou seja, que parte da situação concreta, que repensa a prática e que institui processos de transformação" (GHIGGI, 2010, p. 114).

Para o autor, considerando o olhar sobre a educação popular, percebo que o diálogo toma, como ponto de partida, o quadro antropológico-cultural, o qual está, intimamente, ligado à vida de quem participa da relação educativa, na qual o universo temático, como o mundo da cultura dos sujeitos envolvidos, permite a construção do universo vocabular.

Reconheço que a partir do diálogo com os sujeitos, irá nascer a problematização do tema gerador como o universo mínimo temático. Esse universo mínimo é composto por temas os quais, em geral, se contradizem, e por vezes mantêm estruturas já existentes, onde se estabelece 
uma relação de correspondência entre os temas geradores ${ }^{4}$ e o contexto histórico do qual os seres humanos fazem parte, possibilitando perceber a inserção dos envolvidos na temática.

O senhor argumentou, ainda, que os temas geradores, não raro, encontram-se encobertos pelo que compreende como "situações-limites" as quais se apresentam como determinantes históricas permitindo aos seres uma adaptação a realidade em que se encontram. Quando os seres humanos não estão envolvidos e envolvendo as "situações-limites" as respostas desses não serão autênticas. Dessa maneira, acabam por atuar a favor da elite dominante a qual estão submetidos, não transpondo as "situações-limites".

Um exemplo de uma "situação-limite" apontado pelo senhor, em encontro pessoal com os operários no nordeste brasileiro, ocorrido no centro social do SESI no Recife é citado na obra Pedagogia da esperança. O senhor argumentava para um grupo de pais e mães sobre autoridade, liberdade, castigo e prêmio em educação, contando depois sobre a teoria de Piaget e seus aspectos positivos de não se bater nos filhos, defendendo, ainda, uma relação dialógica, amorosa entre pais, mães, filhas e filhos, substituindo o uso dos castigos violentos. Nesse momento, levantou-se um pai, aparentando uns 40 anos e pediu a palavra. Esse fez um discurso que o senhor diz jamais poder esquecer, que o acompanhou vivo na memória. O senhor acrescenta que muitos anos depois percebeu o dito como saber de classe.

Nessas circunstâncias, o sujeito pediu a palavra e começou e questionar se o senhor saberia onde eles moravam e se o senhor já teria visitado a casa de algum deles. Passou, em seguida, a descrever as características precárias das casas onde viviam, com limites ínfimos e sem recursos para as mínimas necessidades. Falou da proibição que lhes era imposta de serem felizes, de que pudessem ter esperança em algo melhor.

O senhor nos conta, ainda, que conforme a conversa ia se desenvolvendo o senhor se afundava na cadeira, procurando uma saída para os questionamentos. Finalmente, depois de um silêncio de alguns segundos, passeou os olhos pelo auditório inteiro, e fitando Freire outra vez disse: “- Doutor, nunca fui a sua casa, mas vou dizer ao senhor como ela é. Quantos filhos têm?

\footnotetext{
${ }^{4}$ Para Brandão (2013) os temas geradores se constituem a partir de temas concretos da vida que "[...] espontaneamente aparecem quando se fala sobre ela, sobre seus caminhos" (BRANDÃO, 2013, p. 39) e remetem a questões que são das relações dos seres humanos como: “[...] seu meio ambiente, a natureza, através do trabalho; com a ordem social da produção de bens sobre a natureza; com as pessoas e grupos de pessoas dentro e fora dos limites da comunidade, da vizinhança, do município, da região; com valores, símbolos e ideias" (BRANDÃO, 2013, p. 39).

${ }^{5}$ Para Osowski (2010, p. 375) as "situações-limites" são “[...] constituídas por contradições que envolvem os indivíduos, produzindo-lhes uma aderência aos fatos e, ao mesmo tempo, levando-os a perceberem como fatalismo aquilo que lhes está acontecendo. Como não conseguem afastar-se disso, nem se percebem com algum "empowerment", aceitam o que lhes é imposto, submetendo-se aos acontecimentos. Eles não têm consciência de sua submissão porque as próprias situações-limites fazem com que cada um sinta-se impotente diante do que lhe acontece".
} 
É tudo menino? - Cinco - disse ele afundando-se mais ainda na cadeira. - Três meninas e dois meninos" (FREIRE, 2002, p. 25).

A partir daí o sujeito descreveu a sua casa de forma que "[...] não havia nada a acrescentar, nem a retirar" (FREIRE, 2002, p. 25). Casa com pátio, um quarto para os meninos e outro para as meninas, um quarto para o casal, quarto de empregada bem menor que dos filhos e do lado de fora de casa, uma biblioteca, cozinha com a "linha Arno" e um jardim com grama inglesa. Falou sobre os operários chegarem em casa cansados do trabalho, encontrarem as crianças sem banho, com fome, agitadas, muito diferente de quando o senhor chegava em casa e encontrava as crianças de banho tomado, limpas e alimentadas. Acrescentou, ainda, que por ter que levantar às quatro da manhã do outro dia "[...] pra começar tudo de novo, na dor, na tristeza, na falta de esperança [...] se a gente bate nos filhos e até sai dos limites não é porque a gente não ame eles não. É porque a dureza da vida não deixa muito para escolher" (FREIRE, 2002, p. 25).

No caso descrito pelo senhor há uma "situação-limite" expressa na impossibilidade de transformar a condição dura da vida operária no contexto da periferia do Recife, naquele momento histórico do final dos anos 50. Por outro lado, na capacidade daquele operário de diferenciar sua situação da de um "doutor", no caso a sua situação, está o saber de classe, que pode ser o esboçado a partir de uma leitura crítica de realidade, possível de ser germe da superação da "situação-limite".

Por outro lado, na superação, no momento em que, na ação, se instaura a percepção crítica irá “[...] se desenvolver um clima de esperança e confiança que leva os homens a se empenharem na superação das 'situações-limites'” (FREIRE, 2004, p. 91, grifo do autor). Nesse contexto, quando os seres humanos se percebem na fronteira entre o ser e o "ser mais" está implícito o "inédito viável”, como aqueles projetos e atos das possibilidades humanas, com intensidade afetiva, cognitiva, política e ética.

Essa relação dialética entre condicionamentos e liberdade persiste na realidade, pois da mesma maneira que os oprimidos tentam concretizar o "inédito-viável" os opressores tentam evitar as "situações-limites". A proposta freiriana enfatiza que a percepção dos temas geradores acontece no momento em que os seres humanos, ao mesmo tempo, percebem os temas em que estão envolvidos e, ainda, esses temas envolvem as "situações-limites", estabelecendo, assim, uma dimensão crítica.

Problematizados os temas geradores, o senhor argumentou sobre a importância da investigação temática. Essa possui por objetivo, quando os seres humanos não captam as “situações-limites" em sua globalidade, empreender em manifestações periféricas. Não raro, o 
exercício da investigação temática faz-se presente em função da imobilidade e fragilidade existencial dos seres humanos envolvidos.

$\mathrm{Na}$ sequência, o senhor chamava de "temas de dobradiça" aqueles que eram acrescentados por sugestão dos educadores e se inseriam como fundamentais no corpo inteiro da temática, para melhor esclarecê-la.

A partir de então é possível que se chegue ao "inédito-viável” o qual não é uma simples junção de letras ou uma expressão idiomática sem sentido, mas uma palavra-ação, portanto, a práxis. O “inédito-viável” possui uma carga afetiva, cognitiva, política, epistemológica, ética e ontológica para expressar os projetos e os atos das possibilidades humanas. Está carregada de crenças, valores, sonhos, desejos, aspirações, medos, ansiedades, vontade e possibilidade de saber, fragilidade e grandeza humana. Acima de tudo, segundo Araujo Freire (2010, p. 224), palavra que nos traz a “[...] esperança e o germe das transformações necessárias voltadas para um futuro mais humano e ético, para alcançarmos o destino ontológico da existência humana".

Reflito que o "inédito-viável” não pode ser apreendido no nível da consciência real ou efetiva, mas ao nível da “consciência máxima possível”, de tal maneira, que nos diz que não há o definitivo, o pronto ou, ainda, o acabado. O “inédito-viável” se nutre da inconclusão humana, não tem um fim, um termo definitivo de chegada.

É sempre, pois devenir, pois alcançado o inédito-viável pelo qual sonhamos e lutamos, dele mesmo, já não mais um sonho que seria possível, mas o sonho possível realizando-se, a utopia alcançada, ele faz brotar outros tantos inéditos-viáveis quantos caibam em nossos sentimentos e em nossa razão ditada pelas nossas necessidades mais autênticas (ARAUJO FREIRE, 2010, p. 225).

Ainda segundo a mesma autora, os "inéditos-viáveis" são os sonhos coletivos e devem sempre estar a serviço da coletividade. São democráticos e estão a serviço do mais humano que existe nos seres, induzido a que se crie um novo ser humano para uma sociedade nova: mais justa, menos feia e mais democrática.

Nessas considerações, percebo que a construção do conhecimento mantém sua centralidade a partir do saber popular que é enfatizado e que se gera na prática social pela participação do e com o povo. Por outro lado, reconheço, ainda, como é forte a noção de que educação acontece quando há a transmissão de conteúdos por parte de quem educa.

Mesmo que o senhor e outros pensadores da educação como Dewey, Rogers e Montessori inspirem uma boa parte dos educadores no Brasil pelo mundo afora, as instituições em geral, e falo de quem vive a escola formal há trinta anos, forjam práticas amarradas difíceis de serem superadas. 
Para o senhor, ao contrário trata-se de estabelecer um diálogo, pois significa que aquele que educa está aprendendo também. Tanto educandos quanto educadores são transformados em pensadores críticos. O diálogo é uma relação horizontal que se nutre de amor, humildade, esperança, fé e confiança. Zitkoski (2010) afirma que por meio do diálogo “[...] podemos dizer o mundo segundo nosso modo de ver. Além disso, o diálogo implica uma práxis social, que é o compromisso entre a palavra dita e nossa ação humanizadora. Essa possibilidade abre caminhos para repensar a vida em sociedade" (p. 117).

Diante da pergunta formulada inicialmente, relembrando, como conhecedor dos pobres, das periferias e zonas rurais, e como alguém que se propôs a pensar e reinventar a educação nestes meios, que pistas o senhor indicaria para um trabalho de pesquisa num contexto desses? Acredito oportuno destacar outras categorias, a partir da leitura de outros textos seus e de outros autores que comentaram suas obras e ideias.

\section{Educação e política}

Estou fortemente pressupondo que o que inspira e carrega sua obra são os movimentos sociais populares, quem sabe as marchas que o senhor gostaria de ver se multiplicando na busca de dignidade (STRECK, 2011). O engajamento pela luta da democratização e pelos direitos humanos no Brasil e nos diferentes países que o senhor viveu assim como a construção do poder popular na América Latina mostra que a educação e a política caminham juntas no seu pensamento e na sua prática.

Procurando palavras suas para relacionar esses dois grandes temas da vida e da cultura humana destaco o seguinte: "uma das questões fundamentais [...] a favor de quem e do quê, portanto contra quem e contra o quê fazemos a educação e de a favor de quem e do quê, portanto contra quem e contra o quê, desenvolvemos atividade política (FREIRE, 1987, p 27).

Acredito na necessidade, como o senhor mesmo já enfatizou, de que quanto mais é possível ganhar clareza por meio da prática, mais se torna perceptível a impossibilidade de separar a educação da política.

Gadotti (1996) afirma que a realidade não é pensada pelo senhor da mesma forma que para um sociólogo, que procura apenas entendê-la, mas busca nas ciências (sociais e naturais) por meio de elementos para compreendê-la mais cientificamente e intervir de forma mais eficaz nela. Reflito neste aspecto que Gadotti se referiu a um sociólogo sem leitura crítica, sem compromisso com as classes populares e com a luta pela superação dos abismos de desigualdade existentes no Brasil e nos países periféricos ao capitalismo. 
Acredito pertinente, ainda, citar dois sociólogos comprometidos com as lutas políticas no campo da esquerda como Fernandes (1978), em particular na sua obra A Integração do Negro na Sociedade de Classes, bem como, a partir de sua trajetória no Partido dos Trabalhadores, do qual, também, o senhor participou, e Souza (2017), contemporâneo nosso, que busca construir uma sociologia que rompe com a leitura de que o Brasil é um país vira lata, inferior culturalmente aos países centrais do capitalismo, buscando uma referência sociológica que embase a esquerda política nos seus embates com o neoliberalismo e com as elites de rapina.

"Disse o Papa Pio XI que a Política é a forma mais perfeita da caridade. A fala foi repetida por Paulo VI, por meio de quem veio a se tornar amplamente conhecida e recentemente retomada por Francisco" (FRANCISCO, 2016, p. 1). Confesso ao senhor que tenho pouco conhecimento da política, não sou um estudioso de Maquiavel, Hobbes e outros. Mas fui militante de causas estudantis, sindicais, militei em partido político de esquerda, em movimentos ecológicos e hoje vejo como profundamente política minha ação como educador de escola pública e no trabalho engajado nas comunidades eclesiais da igreja católica.

A política está no âmago daqueles que sonham e atuam a favor da justiça social e, dessa maneira, a educação não é apenas uma ferramenta para a transformação social, ou para a manutenção do status quo, pois ela se inter-relaciona com a política porque tem finalidade e meio, forma, maneira de ser feita. Assim, ela estabelece diálogos ou os cerceia, impedindo o outro de ser por meio da palavra e do corpo.

Tudo o que li, ouvi e vivi sobre educação e política desde minha formação na licenciatura nos anos 80 até os dias de hoje me levam a crer que educação e política são como irmãs: se amam, dão as mãos, brigam, perdoam-se e no fim das contas precisam muito uma da outra.

Meu caro educador Paulo Freire, finalizo essa sessão, retomando sua obra Pedagogia da indignação com a seguinte afirmação: "se a educação sozinha não transforma a sociedade, sem ela tampouco a sociedade muda" (FREIRE, 2014, p. 31).

\section{Otimismo, fé e esperança}

A partir da leitura intitulada $O$ otimismo de Paulo Freire, percebo que Collins (1996) aproxima-se das raízes da problemática que originou esse projeto de pesquisa, gestado em uma comunidade eclesial de base, conforme previamente anunciado. 
Além de poder dialogar com a pergunta formulada o texto de Collins é como uma palavra de paz e de discernimento, uma palavra espiritual e de amor, de orientação para o trabalho de pesquisa do qual a pergunta é parte fundamental. E por que disto? Porque um jesuíta, especialmente um admirador da sua obra e vida, é um homem de fé e, embora não apareça nos adjetivos que Collins atribui ao senhor, parece que esta é uma característica de ambos.

Acredito importante lembrar que a proposta de pesquisa a ser realizada na periferia do município nasce num contexto eclesial, de vivência da fé no serviço às pessoas que estão entre as mais pobres daquela região da cidade. A paróquia, unidade que congrega um dado número de comunidades de base, está sob a coordenação dos padres jesuítas desde 2012.

Chamo a atenção para a primeira biografia do senhor, publicada em 1977, que foi elaborada por um religioso católico. O senhor teve influência religiosa por parte do pai, que frequentava círculos espíritas e da mãe, católica apostólica romana. Segundo Streck (2010) o senhor não se entende como homem religioso, mas isso não quer dizer que negava ou estava alheio às manifestações históricas da espiritualidade.

Em sua juventude vejo que percebe a distância entre o evangelho anunciado e a prática dos cristãos. Pela Ação Católica o senhor argumenta que foi "empurrado" para os mangues e favelas do Recife, de tal maneira, que conheceu e identificou-se com a Teologia da Libertaçãó ${ }^{6}$

Argumenta, ainda, que não foi um teólogo da libertação no sentido acadêmico da palavra, mas sua obra foi e continua sendo matéria prima para qualquer teólogo comprometido com os condenados da terra ${ }^{7}$. O senhor não foi um filósofo cristão, mas um intelectual orgânico que instaurou paralelos comprometidos e criativos entre "[...] filosofia, pedagogia, sociologia, linguística, comunicação e, embora não explicitamente, teologia também" (PREISWERK, 2010, p. 392).

Outro elemento importante da proximidade de sua pedagogia com temas da fé cristã, e, nesse caso, em particular com os jesuítas ${ }^{8}$ é ter como objetivo discernir o maggis, isto é, a vocação para o ser mais dos seres humanos no projeto do Criador.

Uma das obras sociais da Companhia de Jesus é o movimento Fé e Alegria, que possui práticas de contra turno escolar com crianças em situação de vulnerabilidade social em algumas grandes cidades do Brasil e América Latina (Porto Alegre, São Paulo, Salvador, entre outras),

${ }^{6}$ A obra Teologia da libertação de Gustavo Gutierrez foi publicada em 1971, um ano após a Pedagogia do Oprimido.

${ }^{7}$ Fanon (1968) ao comparar as condições sociais entre o colono e o colonizado (os condenados) reflete que a cidade do colonizado é uma cidade faminta de pão, de carne, de sapatos, de carvão, de luz, tal que se constitui como uma cidade "[...] acocorada, uma cidade ajoelhada, uma cidade acuada" (FANON, 1968, p. 29).

${ }^{8}$ A companhia de Jesus é uma ordem religiosa fundada por santo Inácio de Loyola na Europa do início do século XVI. 
tendo o tripé de sua missão alicerçada na espiritualidade inaciana, na ecologia integral e em sua pedagogia.

O senhor falou de uma camaradagem com Cristo, que, para alguns, especialmente quando viveu na Europa, não era compreendida, uma vez que teve Marx como um de seus principais interlocutores.

Em uma entrevista a Cortella e Venceslau (1992) disse que: "Marx me ensinou a compreender melhor os evangelhos. Quem me apresentou a Marx foi a dor do povo [...]. Fui a Marx e não vi razão nenhuma para não continuar minha camaradagem com Cristo. Mas eu não sou um homem religioso" (CORTELLA; VENCESLAU, 1992, p. 38).

O senhor testemunha a sua fé afirmando que esta se funda, sobretudo, na crença da existência de um Deus, que não é o "fazedor" da sua história, da nossa história diria eu, mas é uma presença na história dos seres humanos, na sua crença de que "Deus não mente, Cristo não mente" (CORTELLA; VENCESLAU, 1992, p. 38-39).

Na mesma reportagem o senhor comenta sobre sua juventude, as práticas de fé cristãs católicas, como a confissão, e as dificuldades de viver a sexualidade dentro dos parâmetros orientados por essa mesma fé.

Nem por isso a saída foi o aniquilamento ou a repressão da sexualidade. Como o senhor mesmo afirma, ela foi se expressando nos livros que o senhor escreveu, com o amor à vida que sempre teve. Também sua experiência à frente da secretaria municipal de educação de São Paulo a qual proporcionou vazão à temática da sexualidade em um trabalho que abriu as portas da secretaria para senhora Marta Suplicy e sua equipe a fim de realizarem um trabalho com 5 mil adolescentes na qual tratava a compreensão crítico-amorosa de seus corpos, no intuito de melhorarem seu desempenho com relação à história, à geografia e à matemática, dentre outras.

"É que no fundo a sexualidade, sem querer chegar a nenhum reducionismo, tem muito de centro de nós mesmos. Uma coisa é a sexualidade do fenômeno vital, do animal. A outra é a sexualidade que se inventa, que vira jogo, que vira brinquedo" (CORTELLA; VENCESLAU, 1992, p. 33).

\section{Aprimorando a reflexão}

Se o fundamento para a ação político-educativa emancipatória do senhor está centrado no conceito de "ser mais", então acredito que pesquisar, compreender e perceber os elementos da educação ambiental crítica entre as famílias em situação de vulnerabilidade social faz sentido porque estas, estando abaixo da linha da dignidade humana, são chamadas, ontologicamente 
segundo definido pelo senhor, a outra condição, a de sujeitos de sua própria vida.

Uma possiblidade que reflito é a de aprofundamento desse conceito do "ser mais", de problematizá-lo com as lideranças que trabalham no serviço das cestas básicas e com as próprias famílias que as recebem e, a partir disso, estar sensível às demandas, aos interesses, às necessidades que caminhem no sentido da construção da emancipação.

Um segundo passo no sentido de aproximar a pergunta e as reflexões está naquilo conforme descreve Streck (2011): "Paulo Freire se revela e se constrói nos embates da história por libertação de todas as formas de opressão. É nessa busca que se pode encetar também o diálogo com diferentes disciplinas e tradições culturais" (p. 8).

Percebo nos primeiros diálogos com as famílias a dificuldade de pronúncia da sua palavra. Ainda à época das reuniões com as lideranças e as próprias famílias que recebem a cesta básica em cada uma das comunidades (quatro, cada uma com um grupo que variava de 15 a 35 famílias), foi lançada a questão sobre em que mais poderíamos "ajudá-las". As intervenções eram quase inexistentes e as reuniões quase sempre terminavam com falas das próprias lideranças que tentavam responder a si mesmas.

Para que brotem elementos das "tradições culturais" construídos na vivência e na trajetória histórica daquelas pessoas, que possivelmente por gerações vivem em situação de exclusão, certamente serão necessários instrumentos, técnicas, estratégias adequadas à pronúncia da sua palavra.

A "cultura do silêncio" é "[...] resultado de ações político-culturais das classes dominantes, produzindo sujeitos que se encontram silenciados, impedidos de expressar seus pensamentos e afirmar suas verdades, enfim, negados em seu direito de agir e de serem autênticos"(OSOWSKI, 2010, p. 101).

Se o pressuposto que lhe inspira são os movimentos sociais populares então a pesquisa, o trabalho da rede solidária de uma comunidade eclesial de base, instituição da igreja historicamente sensível às lutas populares, está em comunhão com esses pressupostos.

Outro aspecto que me parece uma pista da experiência do senhor nos meios populares está sendo partilhada por meio das reflexões de Streck (2011) como a relação entre o diálogo com diferentes teorias e seus autores versus a prática. Segundo Streck (2011) o erro está na questão de fazer uma teorização descolada da prática que acaba então em mero verbalismo.

Assim, é necessário um movimento de voltar-se à realidade, de "ad-mirá-la". Aqui o próprio ato de pensar é objeto de reflexão tornando conscientes seus pressupostos e possibilidades de interpretação. Também é preciso entender que não existe uma teoria que precisa ser relacionada com a prática, mas que a teoria é a explicitação de uma prática, estando 
ambas, portanto em permanente recriação.

O desafio para pesquisa talvez seja o de ter clareza sobre que elementos teóricos, construindo o olhar sobre as práticas do dia-a-dia da vida dos atores envolvidos no serviço de arrecadação e distribuição das cestas básicas, assim como, em especial das famílias.

Refletindo sobre um trabalho que acontece em âmbito eclesial parece muito apropriado trazer a observação de Streck (2011) sobre imanência-transcendência que ele percebe na obra do senhor. Trata-se de uma transcendência não dicotomizada da imanência, mas que mantém essas duas expressões da vida humana em tensão (STRECK, 2011, p. 14).

Percebo aqui, movimentos diferentes dentro da igreja católica, nos quais predominam, em alguns, um enfoque maior na transcendência e, em outros, um enfoque maior na imanência. A tensão entre imanência e transcendência presente na obra do senhor pode ser um sinal para uma comunicação complementar entre essas duas dimensões da vida e da vida na igreja.

Pode parecer sem congruência tantos temas serem tratados nessa carta para o senhor. Mas gostaria, ainda, em um esforço final, indicar uma perspectiva que busca unir saberes científicos, e de diferentes campos da ciência, com saberes oriundos dos meios populares e das tradições espirituais. Trata-se da perspectiva ecológica ou do paradigma ecológico.

O termo ecologia é discutido na obra Dicionário Paulo Freire pelo educador Calloni (2010). O mesmo autor reflete, a partir de Fritjof Capra, físico austríaco, sobre a "Ecologia Profunda", como conceito emergente e que aponta para a percepção do reconhecimento “[...] da interdependência fundamental de todos os fenômenos e o fato de que, enquanto indivíduos e sociedades, estamos todos encaixados nos processos cíclicos da natureza" (CAPRA, 1997, p. 25).

O senhor mesmo afirma não acreditar na amorosidade entre os seres humanos, “[...] se não nos tornarmos capazes de amar o mundo" (FREIRE, 2000, p. 67). Dessa maneira, é premente articular a prática educativa de caráter crítico, social e libertador com as questões ecológicas também semelhante ao que o senhor afirmava ao se referir ao final do século XX.

\section{Considerações finais}

As categorias que foram elencadas e explicadas nos parágrafos anteriores sinalizam potencialidades na perspectiva da temática da pesquisa que se encontra em fase de andamento. Estes são os apontamentos que gostaria de discutir com o senhor no contexto da pesquisa sobre como pensar e praticar a educação com famílias em situação de vulnerabilidade social na periferia do município, no sul do Rio Grande do Sul. 
Tanto se forem significativos quanto se não forem importantes estou aberto e desejoso das suas críticas e observações, afinal sou um daqueles que se propõem a aprender ensinando e ensinar aprendendo, como também o senhor mostrou a todos que se interessam por educação, liberdade, transformação social e humanização.

Ainda não tenho claro, educador Freire, como relacionar cada um dos temas tratados com os sujeitos da pesquisa que me proponho a fazer. Talvez existam muitas inquietações e intuições. Uma delas é oportunizar espaços de diálogo nos moldes da pesquisa ação, a fim de problematizar aspectos que surjam do cotidiano dos sujeitos das comunidades com que trabalho, caminhando em sentido contrário a "cultura do silêncio".

É possível que apareçam assuntos que estejam como "situações-limites" na vida dos sujeitos; é possível que a esperança em um “inédito-viável” também se apresente. A perspectiva da teologia da libertação está em tensão com outros, assunto mais para lideranças do que para os sujeitos que recebem as cestas básicas.

O ser mais de cada um, quem sabe com o projeto de economia solidária da rede, possa emergir. A antiga e sempre surpreendente relação entre teoria e prática pode ser outra tensão entre a pesquisa acontecendo em meio a um projeto eclesial que não depende dela, mas a alimenta. A pesquisa também pode vir a alimentar o projeto eclesial de perspectiva emancipatória.

No tema ecologia existe uma pista concreta de trabalho: em uma das reuniões feitas com um grupo de cerca de vinte pessoas entre moradores da comunidade e alguns colegas da pósgraduação o assunto "lixo" apareceu significativamente. De fato, ao lado da sede da comunidade surpreende a se ver tantos resíduos serem descartados inadequadamente.

Já com relação à tensão entre educação e política no contexto da pesquisa creio que seja possível problematizar a forma como se faz no projeto eclesial as formações, ainda com pouco diálogo e dificuldades sobre a cultura do silêncio. Mas, penso que se tenha avançado também. É possível que possa ser problematizado o com quem e contra quem se está lutando; a favor de que e contra o que o suor de todos é investido. Em uma prática educativa com caráter crítico, social e libertador é necessário que estes argumentos fiquem claros, mas há que se ter cuidado para não cair em posições dogmáticas e autoritárias que acabem por afastar as pessoas que tenham perspectivas políticas diferentes, mas não contrárias.

Desde já agradeço sua contribuição simplesmente por me motivar a escrever e pesquisar para que isso possa acontecer; por todos aqueles que contribuíram e contribuem no sentido de conhecer e refletir sobre sua obra e sua vida; e, por fim, pelo testemunho de humildade e amor que foi sua vida. 


\section{REFERÊNCIAS}

ARAUJO FREIRE, Ana Maria. Inédito viável. In: STRECK, Danilo Romeu; REDIN, Euclídes; ZITKOSKI, Jaime José (Orgs.). Dicionário Paulo Freire. 2. ed. Belo Horizonte: Autêntica, p. 224-226, 2010.

BRANDÃO, Carlos Rodrigues. O que é método Paulo Freire. 34. reimp. São Paulo: Brasiliense, 2013.

CALLONI, Humberto. Ecologia. In: STRECK, Danilo Romeu; REDIN, Euclídes; ZITKOSKI, Jaime José (Orgs.). Dicionário Paulo Freire. 2. ed. Belo Horizonte: Autêntica, p. 131-133, 2010.

CAPRA, Fritjof. A teia da vida. São Paulo: Cultrix, 1997.

COLLINS, Denis. O otimismo de Paulo Freire. In: GADOTTI, Moacir (Org.). Paulo Freire: uma biobibliografia. São Paulo: Cortez, p. 589-590, 1996.

CORTELLA, Mário Sérgio; VENCESLAU, Paulo de Traso. Paulo Freire. Revista Teoria \& Debate, São Paulo, n. 17, p. 28-40, jan./mar. 1992.

FANON, Frantz. Condenados da terra. v. 42. 1. ed. São Paulo: Civilização Brasileira, 1968.

FERNANDES, Florestan. A integração do negro na sociedade de classes. v. 1. 3. ed. São Paulo: Àtica, 1978.

FRANCISCO, Felipe Magalhães. A política como forma mais perfeita da caridade.

Domtotal. 2016. Disponível em: https://domtotal.com/noticia/1076008/2016/09/a-politicacomo-forma-mais-perfeita-da-caridade/. Disponível em: dez. 2019.

FREIRE, Paulo. A Importância do ato de ler. São Paulo: Autores Associados/Cortez, 1987.

FREIRE, Paulo. À sombra desta mangueira. São Paulo: Olho d’Água, 1995.

FREIRE, P. Pedagogia da esperança: um reencontro com a pedagogia do oprimido. 9. ed. Rio de Janeiro: Paz e Terra, 2002.

FREIRE, Paulo. Pedagogia do oprimido. 38. ed. São Paulo: Paz e Terra, 2004.

FREIRE, P. Pedagogia da indignação. São Paulo: Paz e Terra, 2014.

GADOTTI, Moacir. Paulo Freire: uma biobibliografia. São Paulo: Cortez, 1996.

GHIGGI, Gomercindo. Paulo Freire e a revivificação da educação popular. Revista Educação, Porto Alegre, v. 33, n. 2, p. 111-118, maio/ago. 2010.

OSOWSKI, Cecília Irene. Cultura do silêncio. In: STRECK, Danilo Romeu; REDIN, Euclídes; ZITKOSKI, Jaime José (Orgs.). Dicionário Paulo Freire. 2. ed. Belo Horizonte: Autêntica, p. 101-102, 2010. 
PREISWERK, Matthias. Teologia da Libertação. In: STRECK, Danilo Romeu; REDIN, Euclídes; ZITKOSKI, Jaime José (Orgs.). Dicionário Paulo Freire. 2. ed. Belo Horizonte: Autêntica, p. 392, 2010.

SOUZA, Jessé. A elite do atraso: da escravidão a lava-jato. Rio de Janeiro: Leya, 2017.

STRECK, Danilo Romeu. Fé. In: STRECK, Danilo Romeu; REDIN, Euclídes; ZITKOSKI, Jaime José (Orgs.). Dicionário Paulo Freire. 2. ed. Belo Horizonte: Autêntica, p. 117-118, 2010

STRECK, Danilo Romeu. Cinco Razões para dialogar com Paulo Freire. Revista ecurriculum, São Paulo, v. 7, n. 3, p. 1-18, dez. 2011.

ZITKOSKI, Jaime José. Diálogo/Dialogicidade. In: STRECK, Danilo Romeu; REDIN, Euclídes; ZITKOSKI, Jaime José (Orgs.). Dicionário Paulo Freire. 2. ed. Belo Horizonte: Autêntica, p. 117-118, 2010.

\section{Como referenciar este artigo}

FARINA, Sinval Martins; FREITAS, André Luis Castro; FREITAS, Luciane Albernaz de Araújo. Carta a Paulo Freire: como superar o assistencialismo por meio de uma prática educativa como caráter crítico-libertador?. Revista on line de Política e Gestão Educacional, Araraquara, v. 24, n. 2, p. 478-493, maio/ago. 2020. e-ISSN: 1519-9029. DOI: https://doi.org/10.22633/rpge.v24i2.13300

Submetido em: 09/12/2019

Revisões requeridas: $10 / 02 / 2020$

Aprovado em: 25/03/2020

Publicado em: 09/04/2020 